\title{
Meta-Analysis on Visual Persuasion- Does Adding Images to Texts Influence Persuasion?
}

\author{
By Kiwon Seo ${ }^{*}$
}

\begin{abstract}
Compared to verbal texts, the effects of visual images on persuasion have not been sufficiently researched. The current meta-analysis investigates this under-tested topic by examining whether adding images to texts influences persuasive outcomes. The literature search found 20 effect sizes from 12 studies with a total of 2,452 participants. The overall effects show that additional visual images to verbal texts had no significant effect on persuasion, $r=0.055, p=0.161$. When moderating variables were included, however, several significant visual effects were emerged, such that photographs $(r=0.077$, $p=0.038)$, positive images $(r=0.185, p=0.000)$, and images about health issues $(r=0.105$, $p=0.015$ ) showed significant advantages of increasing persuasion. Limitations and future directions of the study are also discussed.
\end{abstract}

Keywords: meta-analysis, persuasion, visual image.

\section{Introduction}

Communication scholars have long sought for message characteristics that increase persuasion. Throughout numerous research projects, they have provided convincing evidence that certain message features lead to better persuasion outcomes. The existing research, however, heavily focuses on one specific element in messages-verbal text-and relatively has paid less attention to other portion that also may influence persuasion-visual elements. Visual elements include various visible message components that affect message assessment, including font (Juni \& Gross, 2008), color (Gerend \& Sias, 2009), or images. The current research project focuses on the effects of visual images. Specifically, it examines whether adding images to verbal texts influences persuasion outcomes through a metaanalysis technique.

Few studies reviewed the effects of visual image. There is one outdated metaanalysis of picture effect on comprehension (Readence \& Moore, 1981). A more recent review (Houts, Doak, Doak, \& Loscalzo, 2006) covers various outcomes that visual images have in communicating health-relevant issues, but it utilizes a narrative approach that lacks an overall summary effect size (Borenstein, Hedges, Higgins, \& Rothstein, 2009). Given these limited findings, the current project starts from a relatively basic, straightforward examination of image's persuasive effects: Presence versus absence of images in texts. The following section first reviews the previous literatures that tested the effects of visual images on attention, memory, emotion and persuasion. After this review, two theoretical grounds that account for why additional images to texts can influence persuasion will be discussed.

\footnotetext{
*Assistant Professor, Sam Houston State University, USA.
} 


\title{
Empirical Findings: Research on the Effects of Visual Images
}

\begin{abstract}
Attention
One distinctive feature of visual image is its eye-catching effect (Finn, 1988; MacKenzie, 1986). Using eye-tracking equipment in a laboratory setting, studies have shown that visual images are superior to verbal-only messages in drawing attention (Deubel \& Schneider, 1993), regardless of image sizes (Pieters \& Wedel, 2004). Visual attention refers to an operation that prioritizes a certain part of the brain enhances the activation of information, and diminishes the threshold for processing information (Deubel \& Schneider, 1993). Simply, without specific instructions of message processing or reading order, people tend to first see the visual, rather than verbal part of the message. Attention to visual images also affect subsequent product involvement, attitude, and recall (Rosbergen, Pieters, \& Wedel, 1997).
\end{abstract}

\section{Memorability}

Visual images can also enhance memorability of a message, which is socalled picture superiority effect (Nelson, Reed, \& Walling, 1976). Childers and Houston (1984) found that messages containing visual images produced better recall than verbal-only messages when people did not process the message deeply. Semantically inconsistent visual images to verbal texts enhance memory as well (Houston, Childers, \& Heckler, 1987). On this picture superiority effect, MacInnis and Price (1987) posit that both verbal and visual information processing effectively formulate problems. But verbal information processing contributes an implicit or explicit summary of message-target attributes and features, whereas visual information processing contributes a holistic evaluation of the target. Thus, final outcomes of message recall tend to be differentiated according to the presence of visual images.

\section{Emotion}

Research in consumer psychology has shown that an advertisement can stimulate positive affective experiences, which further lead to increased persuasion outcomes, such as increased positive attitudes toward or behavioral intentions on the advocacies. Escalas (2004) found that positive emotion induced by the combination of a visual image (e.g., running shoes) and mental simulation (e.g., "imagine running in the shoes") effectively mediated the relationship between message and persuasion. Journalism studies also showed that messages containing both verbal and visual components were more effective in arousing positive as well as negative emotions than messages with only verbal component (Domke, Perlmutter, \& Spratt, 2002). Also journalism photographs depicting a negative event (e.g., 9/11 terrorist attack) were highly associated with negative emotions when the event was recalled (Fahmy, Cho, Wanta, \& Song, 2006). In the context of health communication, a negative emotion of fear was found to be more 
aroused by negative visual images and further to mediate the relationship between health messages and persuasion (Seo, Dillard, \& Shen, 2013).

The image's ability to arouse a certain emotional reaction has been also supported by physiological measures, such that seeing emotion-inducing images results in physiological and behavioral responses in consistent patterns (for review, Lang \& Bradley, 2008). Research utilizing functional magnetic resonance imaging (fMRI) found that emotion-arousing visual images activate neural responses in different brain regions (Pessoa, McKenna, Gutierrez, \& Ungerleider, 2002), independent of attention and awareness of emotional visual stimuli (Pessoa, 2005). Investigations using electroencephalography (EEG) also replicated the finding, such that viewing negative or positive images activate emotional reactions in corresponding areas of the brain associated with emotional activations. For example, in Harmon-Jones's (2007) study, when research participants viewed anger-inducing pictures, their left frontal cortical activity, the brain region related to the negative emotion of anger, was increased as well. Together, studies using self-report and physiology measures point out one general conclusion: Visual images can evoke emotional responses.

\section{Persuasion}

When embedded in advocacies, images also affect overall persuasion outcomes. Mitchell (1986) compared positive (sunrise) and negative (wildcat) visual images in advertisements, and found that the positive photograph led to more favorable attitude toward the messages, whereas the reverse was true for the negative one. Peracchio and Myers-Levy (2005) examined moderating role of message involvement in ads (e.g., watch and cereal). They argued that when people are required to process the message systematically, the stylistic properties of images contribute to persuasive outcomes. For example, a vertically oriented object can deliver the meaning of potency, whereas a diagonally oriented one may imply dynamism. Consistent with their reasoning, two experiments showed that compared to verbal only messages, individuals in the systematic processing condition of visual+verbal messages identified the stylistic visual properties of the products and exhibited more favorable attitude toward the stylistic messages. Similarly, Miniard, Bhatla, Lord, Dickson, and Unnava (1991) found that participants in low involvement condition used a peripheral route to make a judgment about an ad, such that when the ad contained an inappropriate, unattractive visual element (iguana), they reduced their product evaluations, whereas the reverse was true for when the ad included an appropriate, attractive element.

As reviewed so far, existing research points out the potential of visual images to influence various outcomes, directly or indirectly related to persuasion. Although most studies do not explicitly employ a specific theoretical framework, several theories provide useful accounts for why visual images are differently processed and have distinctive effects on persuasion. The following section reviews two such theories, dual coding theory and exemplification theory. 


\section{Theories of Visual Image}

\section{Dual Coding Theory}

The basic assumption of dual coding theory (Paivio, 2007) is that we build our knowledge structure from our own "perceptual, behavioral, and affective experiences with the world" and "these experiences become internalized so that cognitive representations and process are modality-specific" (p. 25). We come to know about reality based on modality-specific experiences (e.g., visual, auditory, and haptic) as our physical sensors perceive them. For instance, when we eat a certain food, we acknowledge the tastes as our gustation sensors perceive, and then we internalize, memorize, and evaluate the tastes, which results in the knowledge structure of the food. These experiences are fundamentally different from those of verbal language. In other words, word depictions of the food in terms of texture and taste are inherently different from what the physical sensors perceive, because the depictions are symbolic representations of sensory experiences, not the experiences themselves. Likewise, seeing a visual image is intrinsically different from verbal depictions of the image.

Dual coding theory classifies two functionally independent but interconnected mental subsystems: verbal and nonverbal systems. This classification is made because human beings use verbal language to think, memorize, and communicate information, but at the same time, we also utilize nonverbal information to fulfill those purposes. With the two subsystems, individuals can interpret the meaning of external stimuli by perceiving their verbal or nonverbal specific features (i.e., representational meaning) or by associating the modality specific meaning of verbal and nonverbal features (i.e., referential meaning or associative meaning). For example, when we see a photograph of a dove, we can simply perceive the object as it is seen or we can connect the object with a verbal description of "dove." The latter, associative meaning is possible because of the interconnection between two systems. Crucially, when stimuli contain both verbal and nonverbal information, verbal and nonverbal subsystems interact with each other by reinforcing or amplifying information processing, so that messages with both information types may exert more powerful message effects than messages with a single information type.

\section{Exemplification Theory}

Exemplification theory (Zillmann, 1999, 2002) postulates that human beings have evolved to pay special attention to vital events in facing with numerous external events for their welfare and survival. In contrast, trivial and irrelevant events do not receive much attention because of limited cognitive capacity. The limited capacity is also applied to vital and relevant events, so rather than processing and memorizing each individual event, human beings have evolved to selectively extract essential features of the events and to classify them into a broader category. This classification of numerous events enabled human beings to aggregate limited numbers of individual cases, so that they could use relatively 
small number of experiences to perceive and interpret a large body of similar events. The broader category acts as an exemplar.

Although exemplification theory does not particularly assume that exemplification effect is achieved through a certain message type (e.g., verbal message or verbal+visual message), studies based on this theory often employ visual images to present concrete exemplars (i.e., the "dominance of exemplification by images"; Zillmann, 2002, p. 29). Indeed, one major assumption of the theory is that concrete events are better than abstract ones for comprehension, storage, and retrieval of information. Compared to solely verbal texts, verbal+visual messages are more effective and concrete in exemplifying events, so that message recipients can easily perceive and comprehend the issue under consideration. For instance, Gibson and Zillmann (2000) examined effects of visual exemplars on risk perception with varying degrees of image depictions and they found that visual images produced the highest risk perception about the issue.

The following section discusses potential moderating variables that may interact with visual images. Existing literatures suggest three important moderators: Visual type, visual valence, and message topic.

\section{Moderators of Visual Persuasion}

First, different visual types, such as photograph, drawing, cartoon, graph, and etc., were identified because they are likely to have distinctive effects. According to Peirce (1935), characteristics associated with visual image are broadly classified into three groups: (a) resemblance to the referent (icon; e.g., photographs or pictures), (b) logical relationship between visual image and its meaning (index; e.g., figures, tables, or journalism photos that indicate something happened, acting as a proof), and (c) socially constructed meaning manifested by visual image (symbol; e.g., a national flag symbolizes the nation). This classification shows that because of their unique characteristics, each visual group tends to have different effects on communication process. For example, one distinct characteristic associated with iconic image is its ability to evoke a certain emotion (Joffe, 2008; Messaris, 1997), but in general, it is unlikely to be true to figures or tables. There may be some cases that figures or tables lead to emotional responses (e.g., a stunning fact described in a figure), but the quality and intensity of emotional experience may not be the same as that one receives from appreciating iconic images of beautiful landscapes or cute animals. Accordingly, it is necessary to distinguish each visual group and assess its effects separately.

Second, the valence of visual images was examined. As shown by message framing research (for review, O'Keefe \& Jensen, 2006), messages can emphasize different aspects of issues, which may result in different persuasion outcomes. Likewise, visual images can highlight specific parts of the message by showing positive, neutral, or negative aspects of the issue. Of course, there are various configurations of visual depictions other than the positive versus negative valence, but, as in framing research, the visual valence classification is so basic and straightforward that should be examined prior to other specifications. 
The third moderator, message topic, was closely related to visual valence, because some message topics intrinsically require positive or negative images to exemplify the issues under consideration. For instance, product or service advertisements used positive images to formulate optimistic and desirable impressions about the topic, whereas news stories often showed relatively negative examples or consequences of events, such as war, terrorism, drugs, or illegal immigration. As speculated by exemplification theory, visual exemplars may interact with certain message topics to enhance or diminish the visual effects. The moderator of message topic will examine this possibility.

\section{Methods}

\section{Literature Search}

To locate relevant reports, two undergraduate research assistants searched databases after receiving a 15-hour training that covered the purpose of this research, method of literature search, and inclusion and exclusion criteria. The searched databases included Communication and Mass Media Complete, PsycINFO, EBSCO, Educational Resources Information Center (ERIC), Business Source Complete, and Nursing and Allied Health Source. The search terms were the combinations of the following keywords: visual, image, photograph, photo, illustration, infographic, picture, cartoon, persuasion, attitude, perceived effectiveness, intention, and behavior. Image-relevant words were used in one search box as an independent variable, and persuasion-related words for another box as a dependent variable. When the assistants were unsure of whether the report met the inclusion criteria, they were instructed to include it anyway for the primary researcher to reexamine it later.

\section{Inclusion and Exclusion Criteria}

In the search, four criteria were applied. First, studies must use visual images as the main stimuli. Visual images are various static pictorial presentations in print or web-based forms, including photographs, pictures, illustrations, infographics (e.g., figures or graphs), cartoons, and so forth. Studies using video materials as main stimuli (e.g., Charry, 2014) were excluded because videos contain series of moving images and audio sound that may have distinctive effects compared to static visual images. Second, studies must utilize an experiment or field study design that compared a treatment group receiving messages of visual+verbal information and a control group reading no-image, verbal text-only messages. This criterion was imposed to examine relative effectiveness or ineffectiveness of visual image on persuasion compared to non-image message. Studies that compared different type of visual images (e.g., McQuarrie \& Mick, 1999; van Rompay, de Vries, \& van Venrooij, 2010), intensity of image descriptions (e.g., Kang \& Lin, 2015; Verlhiac, Chappé, \& Meyer, 2011), or a visual treatment group with a control group of no message recipients (e.g., Marshall, Craun, \& Theriot, 2009) were excluded from the main analysis. Third, the dependent variable must be 
persuasion, assessed by attitude change, behavioral intention, perceived effectiveness, behavioral change, or a combination of thereof. When a study employed multiple measures for persuasion (e.g., measuring attitude, behavioral intention, and perceived effectiveness in one study), the mean of the multiple measures was calculated and used as a single effect size for that study (O'Keefe \& Jensen, 2006). Finally, studies must provide statistical information to calculate the effect sizes. When studies did not provide any statistical information (e.g., Süssenbach, Niemeier, \& Glock, 2013), inaccurate information (e.g., Labranche, Helweg-Larsen, Byrd, \& Choquette, Jr, 1997), or insufficient information (e.g., Whatley, Mamdani, \& Upshur, 2002), they were excluded from the main analysis.

\section{Classification of Moderating Variables}

As discussed before, three moderating variables were identified and analyzed. First, visual type was categorized as either photograph or drawing. Contrary to our initial expectation that various image types would be emerged from the search, there were only two types of visual images. Drawing images included graphic illustrations, picture, or cartoons. The second moderator of visual valence was coded as positive, neutral, or negative. Positive images depicted desirable outcomes of advocated topic. Negative images were aversive and unwanted consequences of message depictions, such as war casualties, coffins, and troubled facial expressions. Neutral images did not possess a specific valence, but presented products, exemplars, or behaviors that acted as proofs. When a message contained both positive and negative images, and different statistics associated with separate positive or negative images were not available, the valence was coded as neutral. The last moderating variable was message topic, involving categories of advertisements, news articles, health issues, or information. Advertisements used images to exemplify the products or outcomes related to the message recommendations. In the case of news articles, the messages were selected or modified from actual news stories. Health issues were messages that advocated specific courses of action to improve or maintain individuals' health. Information messages only presented facts (e.g., contact information) or procedures (e.g., solving mathematics).

\section{Calculating Effect Sizes}

The unit of analysis for effect size was an experimental pair that a treatment condition of visual+verbal message was contrasted with a control condition of verbal-only message. There were several studies that employed multiple experiments or multiple group comparisons. As a result, 20 effect sizes from 12 studies were included in the analysis. When a study reports different statistics for different images (e.g., Willnat, Graf, \& Brewer, 2000), we calculated the statistics separately, but if it reports a combined result (e.g., Kelly, Slater, \& Karan, 2002), we calculated the result as one image effect. The statistics used in the calculation were correlations, sample sizes, means, and standard deviations. These were converted to a correlation $(r)$, an effect size indicator, and $p$ value. 


\section{Results}

\section{Effects of Visual Images}

Effect sizes were available for 20 cases with a total of 2,515 participants. A random-effects model was used instead if a fixed-effects model because of an interest in generalizing across messages (Borenstein et al., 2009). Details for each case are summarized in Table 1 . Across 20 effect sizes, additional visual images to verbal texts had a nonsignificant persuasive advantage, $r=0.055, p=0.161$.

Table 1. Sample Sizes, Correlations, and Moderating Variables

\begin{tabular}{|c|c|c|c|c|c|c|}
\hline Study Name & $N$ & $r$ & $p$ value & Visual Type & $\begin{array}{c}\text { Visual } \\
\text { Valence }\end{array}$ & $\begin{array}{l}\text { Message } \\
\text { Topic }\end{array}$ \\
\hline Kelly et al. (2002) & 384 & 0.162 & 0.001 & Photograph & Positive & Ad \\
\hline $\begin{array}{l}\text { Kisielius and Sternthal } \\
\text { (1984) Pilot Study }\end{array}$ & 43 & -0.368 & 0.009 & Drawing & Neutral & Ad \\
\hline $\begin{array}{l}\text { Kisielius and Sternthal } \\
\text { (1984) Study } 1\end{array}$ & 90 & -0.141 & 0.177 & Drawing & Neutral & Ad \\
\hline $\begin{array}{l}\text { Kisielius and Sternthal } \\
\text { (1984) Study } 2\end{array}$ & 58 & -0.231 & 0.069 & Drawing & Neutral & Ad \\
\hline $\begin{array}{l}\text { Kisielius and Sternthal } \\
\text { (1984) Study } 3\end{array}$ & 58 & 0.081 & 0.533 & Drawing & Neutral & Ad \\
\hline Martin (2004) & 160 & 0.312 & 0.000 & Photograph & Positive & Ad \\
\hline $\begin{array}{l}\text { McClure et al. (2011) } \\
\text { Positive Image }\end{array}$ & 115 & -0.050 & 0.592 & Photograph & Positive & News \\
\hline $\begin{array}{l}\text { McClure et al. (2011) } \\
\text { Negative Image }\end{array}$ & 130 & 0.146 & 0.092 & Photograph & Negative & News \\
\hline $\begin{array}{l}\text { Möller et al. (2012) } \\
\text { Drawing }\end{array}$ & 77 & 0.136 & 0.227 & Drawing & Neutral & Information \\
\hline $\begin{array}{l}\text { Möller et al. (2012) } \\
\text { Photograph }\end{array}$ & 77 & 0.035 & 0.758 & Photograph & Neutral & Information \\
\hline Pfau et al. (2006) & 118 & 0.021 & 0.819 & Photograph & Negative & News \\
\hline Sengül and Dereli (2013) & 61 & 0.462 & 0.000 & Drawing & Neutral & Information \\
\hline $\begin{array}{l}\text { Seo and Dillard (in press) } \\
\text { Gain-Match }\end{array}$ & 154 & 0.123 & 0.124 & Photograph & Positive & Ad \\
\hline $\begin{array}{l}\text { Seo and Dillard (in press) } \\
\text { Loss-Match }\end{array}$ & 145 & 0.056 & 0.500 & Photograph & Negative & Ad \\
\hline Seo et al. (2013) Flossing & 252 & 0.043 & 0.491 & Photograph & Neutral & Health \\
\hline $\begin{array}{l}\text { Seo et al. (2013) } \\
\text { Sunscreen }\end{array}$ & 252 & 0.156 & 0.012 & Photograph & Neutral & Health \\
\hline Shahab et al. (2007) & 23 & .207 & 0.308 & Photograph & Neutral & Health \\
\hline Tukachinsky et al. (2011) & 81 & -0.334 & 0.001 & Photograph & Negative & News \\
\hline $\begin{array}{l}\text { Willnat et al. (2000) } \\
\text { Drug }\end{array}$ & 88 & 0.025 & 0.817 & Photograph & Negative & News \\
\hline $\begin{array}{l}\text { Willnat et al. (2000) } \\
\text { Terrorism }\end{array}$ & 86 & 0.086 & 0.424 & Photograph & Negative & News \\
\hline Total $N$ & 2452 & & & & & \\
\hline Mean correlation & & 0.055 & 0.161 & & & \\
\hline
\end{tabular}

Moderator: visual type. As shown in Table 2, when the moderating variable of visual type was examined, messages with photographic images had a weak, but significant effect on persuasion, $r=0.077, p=0.038, k=14$, compared to 
verbal text messages. The messages with drawings did not have an effect on persuasion, $r=-0.003, p=0.982, k=6$.

Moderator: visual valence. Positive images showed a significant effect on persuasion ( $r=0.185, p=0.000)$, although only four cases were included in the analysis. The most cases belong to neutral images $(k=10)$, but the effect was nonsignificant, $r=0.043, p=0.520$. Likewise, negative images did not have a significant effect on persuasion $r=-0.030, p=0.616, k=6$.

Moderator: message topic. In the case of message topic, health issues had a significant effect on persuasion, $r=0.105, p=0.015, k=3$, but again, few cases were included in the analysis. The other topics, ad $(r=0.024, p=0.735, k=8)$, news story $(r=-0.015, p=0.822, k=6)$, and information $(r=0.218, p=0.109$, $k=3$ ), failed to show a significant effect.

Table 2. Summary Results by Moderating Conditions

\begin{tabular}{|l|c|c|c|c|}
\hline Moderators & $k$ & $\%$ & $r$ & $p$ \\
\hline Visual Type & & & & \\
\hline Photograph & 14 & 70 & 0.077 & 0.038 \\
\hline Drawing & 6 & 30 & -0.003 & 0.982 \\
\hline Visual Valence & & & & \\
\hline Positive & 4 & 20 & 0.185 & 0.000 \\
\hline Neutral & 10 & 50 & 0.043 & 0.520 \\
\hline Negative & 6 & 30 & -0.030 & 0.616 \\
\hline Message Topic & & & & \\
\hline Ad & 8 & 40 & 0.024 & 0.735 \\
\hline News & 6 & 30 & -0.015 & 0.822 \\
\hline Health & 3 & 15 & 0.105 & 0.015 \\
\hline Information & 3 & 15 & .218 & .109 \\
\hline Total experimental pairs & 20 & & & \\
\hline
\end{tabular}

Note: Effect size calculations were based on the random effects mode; $k=$ number of experimental pairs.

\section{Discussion}

The main purpose of this project was to examine whether additional images to verbal texts affect persuasion. Results from the meta-analysis with 20 effect sizes show that adding images to messages does not affect overall persuasion outcomes, measured by attitude, perceived effectiveness, behavioral intention, or behavioral change $(r=0.055, p=0.161)$.

Unlike theoretical speculations suggested before, visual images that were presumed to exemplify the message topics or to buttress the verbal descriptions of the messages did not actually influence the overall persuasion effects. However, when moderating variables were included in the analyses, certain visual conditions changed the impact of visual images. In the case of visual type, photographic images showed a significant effect in increasing persuasion $(r=0.077, p=0.038)$, 
but drawings, cartoons, or line illustrations did not $(r=-0.003, p=0.982)$. As suggested by exemplification theory (Zillmann, 1999, 2002), this relative effectiveness seems to come from photographs' ability to visualize and exemplify the message topic in more concrete and realistic ways. Although drawings, cartoons, or line illustrations are iconic signs that indicate resembled referents (Peirce, 1935), their quality and strength of representing direct reference are unlikely to be as strong as photographs. The qualities of experimental stimuli in the analyzed studies are unclear, because most of them did not include the stimuli in the reports. In the case that a study included the stimuli (e.g., Möller et al., 2012), however, the qualities of drawing are not as good and clear as those of photographs. Of course, this speculation, the persuasive quality difference between different types of visual images, needs further investigation, but still the moderator analysis presents an obvious, but important idea on visual persuasion: All images do not equally produced to enhance persuasion, and their qualities must be considered.

The analysis on the second moderator, visual valence, shows that positive images have significant effects $(r=0.185, p=0.000)$ on amplifying persuasion, but neutral $(r=0.043, p=0.520)$ and negative $(r=-0.030, p=0.616)$ did not. Those positive images were magazine advertisements of cigarette, beer, and soft drink (Kelly et al., 2002), a nonstereotypical and positive presentation of an obese woman (McClure et al., 2011), and a group of smiling people (Seo \& Dillard, in press). Because only three studies were included to the positive image category, it is still vague what aspect of these positive images showed significance. However, when other moderators are considered together, a clue can be found. The positive images were all photographs that were used to promote products (Kelly et al., 2002), a service (Seo \& Dillard, in press), or perception about a group of people (McClure et al., 2011). It appears that positive images containing certain characteristics, such as (a) realistic and clear presentations with photographs and (b) desirable and beneficial aspects of the topic.

In the case of the last moderator, message topic, the result indicates that health relevant messages enhanced persuasion $(r=0.105, p=0.015)$, but advertisement $(r=0.024, p=0.735)$, news $(r=-0.015, p=0.822)$, and informational $(r=0.218$, $p=0.109$ ) messages failed to do so. The health studies included neutrally valenced photographs that promoted healthy behaviors, similar to the moderator of visual valence. Interestingly, advertisement messages, which are closer to the idea of promotion, did not show significant effects. This nonsignificant effect mainly resulted from four effect sizes of Kisielius and Sternthal's (1984) study. They tested such conditions where visual images diminished the persuasion because of higher cognitive elaboration. The images were not photographs, but line drawings that might have had distinctive effects. Importantly, contrary to other studies, they forced participants to watch and read the ad messages in 14 pages for 5 seconds for each page. Given that the advocated topic, a new shampoo, was relatively a low involved one, this forced exposure might have acted as a confounding variable that decreased image effects. In fact, a moderator analysis without Kisielius and Sternthal (1984) show that the ad messages have a significant effect on increasing persuasion $(r=0.167, p=0.001)$. Thus, promotional images seemed to be more 
advantageous to increase persuasive outcomes.

Despite the nonsignificance of overall, additional image effect, the analyses of three moderating variables present specific image characteristics that are more likely to amplify persuasive effects. That is, (a) photographs, rather than graphic illustrations, that depict (b) positive and desirable aspects of the topic in (c) promotional messages that advocate a certain service, product, or course of action can be more persuasive. These findings, again, must be interpreted carefully, because these significant effect sizes are very small. For these findings to be more valuable and practical, more studies must be conducted.

\section{Limitations and Future Directions}

The current project is not free from several limitations. First, despite the extensive search for all relevant publications, it is possible for the search to have missed relevant studies. Because this study employed relatively specific exclusion and inclusion criteria, the possibility may be even higher than other searches with broad criteria. Second, this study only compared the presence and absence of visual images, which might have unnecessarily limited the scope of visual research. Given that there is no meta-analysis on the persuasive effects of visual image, it was determined to seek for the basic examination of visual effects. However, many studies have investigated the effects through different designs and comparisons (e.g., Gardner \& Houston, 1986; Smith, Houston, \& Childers, 1985) and found meaningful results. Thus, other studies of visual effects, beside the comparison of presence versus absence of images, should be investigated by future studies. Lastly, this study examined only three moderating variables, but other moderators are also likely to affect persuasive effects of visual images. For example, as reviewed before, many studies have found superior effects of visual images on attention, memory, and emotion, which are all relevant to persuasion. Among them, emotion is a direct and powerful outcome that influences the persuasion (Dillard \& Peck, 2001; Dillard \& Seo, 2013). Because there were few studies that actually measured emotional responses from visual images, it was not feasible to examine emotional effects. As more studies test images' ability to evoke emotions and their associations with persuasion, specific conditions of images' superior effects can be better understood.

\section{Acknowledgements}

This research project was funded by the Faculty Research Grant (FRG) at Sam Houston State University in 2016. 


\section{References}

Borenstein, M., Hedges, L. V, Higgins, J. P. T., \& Rothstein, H. R. (2009). Introduction to meta-analysis. West Sussex, United Kingdom: Wiley.

Charry, K. (2014). Product placement and the promotion of healthy food to preadolescents: When popular TV series make carrots look cool. International Journal of Advertising, 33, 599-616.

Childers, T. L., \& Houston, M. J. (1984). Conditions for a picture-superiority effect on consumer memory. Journal of Consumer Research, 11, 643-654.

Deubel, H., \& Schneider, W. X. (1993). There is no expressway to comprehensive theory of the coordination of vision, eye movements, and visual attention. Behavior and Brain Sciences, 16, 575-576.

Dillard, J. P., \& Peck, E. (2001). Persuasion and the structure of affect: Dual systems and discrete emotions as complementary models. Human Communication Research, 27, $38-68$

Dillard, J. P., \& Seo, K. (2013). Affect and persuasion. In J. P. Dillard \& L. Shen (Eds.), The SAGE handbook of persuasion (2nd ed., pp. 150-166). Thousand Oaks, CA: Sage.

Domke, D., Perlmutter, D., \& Spratt, M. (2002). The primes of our times? An examination of the 'power' of visual images. Journalism, 3, 131-159.

Escalas, J. E. (2004). Imagine yourself in the product: Mental simulation, narrative transportation, and persuasion. Journal of Advertising, 33, 37-48.

Fahmy, S., Cho, S., Wanta, W., \& Song, Y. (2006). Visual agenda-setting after 9/11: Individuals' emotions, image recall, and concern with terrorism. Visual Communication Quarterly, 13, 4-15.

Finn, A. (1988). Print ad recognition readership scores: An information processing perspective. Journal of Marketing Research, 25, 168-177.

Gardner, M. P., \& Houston, M. J. (1986). The effects of verbal and visual components of retail communications. Journal of Retailing, 62, 64-78.

Gerend, M. A., \& Sias, T. (2009). Message framing and color priming: How subtle threat cues affect persuasion. Journal of Experimental Social Psychology, 45, 999-1002.

Gibson, R., \& Zillmann, D. (2000). Reading between the photographs: The influence of incidental pictorial information on issue perception. Journalism and Mass Communication Quarterly, 77, 355-366.

Harmon-Jones, E. (2007). Trait anger predicts relative left frontal cortical activation to anger-inducing stimuli. International Journal of Psychophysiology, 66, 154-160.

Houston, M. J., Childers, T. L., \& Heckler, S. E. (1987). Picture-word consistency and the elaborative processing of advertisements. Journal of Marketing Research, 24, 359369.

Houts, P. S., Doak, C. C., Doak, L. G., \& Loscalzo, M. J. (2006). The role of pictures in improving health communication: A review of research on attention, comprehension, recall, and adherence. Patient Education and Counseling, 61, 173-190.

Joffe, H. (2008). The power of visual material: Persuasion, emotion and identification. Diogenes, 55, 84-93.

Juni, S., \& Gross, J. S. (2008). Emotional and persuasive perception of fonts. Perceptual and Motor Skills, 106, 35-42.

Kang, J., \& Lin, C. (2015). Effects of message framing and visual-fear appeals on smoker responses to antismoking ads. Journal of Health Communication, 20, 647-655.

Kelly, K. J., Slater, M. D., \& Karan, D. (2002). Image advertisements' influence on adolescents' perceptions of the desirability of beer and cigarettes. Journal of Public 
Policy \& Marketing, 21, 295-304.

Kisielius, J., \& Sternthal, B. (1984). Detecting and explaining vividness effects in attitudinal judgments. Journal of Marketing Research, 21, 54-64.

Labranche, E. R., Helweg-Larsen, M., Byrd, C., \& Choquette, Jr, R. A. (1997). To picture or not to picture: Levels of erotophobia and breast self-examination brochure techniques. Journal of Applied Social Psychology, 27, 2200-2212.

Lang, P. J., \& Bradley, M. M. (2008). Appetitive and defensive motivation is the substrate of emotion. In A. Elliot (Ed.), Handbook of approach and avoidance motivation (pp. 51-66). New York, NY: Taylor \& Francis.

MacInnis, D. J., \& Price, L. L. (1987). The role of imagery in information processing: Review and extensions. Journal of Consumer Research, 13, 473-491.

MacKenzie, S. B. (1986). The role of attention in mediating the effect of advertising on attribute importance. Journal of Consumer Research, 13, 174-195.

Marshall, H. L., Craun, S. W., \& Theriot, M. T. (2009). The big picture: How social work can effectively utilize photographs. Social Work, 54, 317-325.

Martin, T. (2004). The alma mater ask: An examination of visual and textual exemplification effects in university web-based fundrasing. Paper presented at the annual meeting of the International Communication Association, New Orleans, LA.

McClure, K. J., Puhl, R. M., \& Heuer, C. A. (2011). Obesity in the news: Do photographic images of obese persons influence antifat attitudes? Journal of Health Communication, 16, 359-371.

McQuarrie, E. F., \& Mick, D. G. (1999). Visual rhetoric in advertising: Text-interpretive, experimental, and reader-response analyses. Journal of Consumer Research, 26, 3754.

Messaris, P. (1997). Visual persuasion: The role of images in advertising. Thousand Oaks, CA: Sage Publications.

Miniard, P. W., Bhatla, S., Lord, K. R., Dickson, P. R., \& Unnava, H. R. (1991). Picturebased persuasion processes and the moderating role of involvement. Journal of Consumer Research, 18, 92-107.

Mitchell, A. (1986). The effect of verbal and visual components of advertisements on brand attitudes and attitude toward the advertisement. The Journal of Consumer Research, 13, 12-24.

Möller, B., Brezing, C., \& Unz, D. (2012). What should a corporate website look like? The influence of Gestalt principles and visualisation in website design on the degree of acceptance and recommendation. Behaviour \& Information Technology, 31, 739751.

Nelson, D. L., Reed, V. S., \& Walling, J. R. (1976). Pictorial superiority effect. Journal of Experimental Social Psychology: Human Learning and Memory, 2, 523-528.

O'Keefe, D. J., \& Jensen, J. D. (2006). The advantages of compliance or the disadvantages of noncompliance? A meta-analytic review of the relative persuasive effectiveness of gain-framed and loss-framed messages. Communication Yearbook, 30, 1-43.

Paivio, A. (2007). Mind and its evolution: A dual coding theoretical approach. New Jersey: Lawrence Erlbaum Associates.

Peirce, C. S. (1935). Collected papers of Charles Sanders Peirce. Belknap Press of Harvard University Press.

Peracchio, L. A., \& Meyers-Levy, J. (2005). Using stylistic properties of ad pictures to communicate with consumers. Journal of Consumer Research, 32, 29-40.

Pessoa, L. (2005). To what extent are emotional visual stimuli processed without attention and awareness? Current Opinion in Neurobiology, 15, 188-196.

Pessoa, L., McKenna, M., Gutierrez, E., \& Ungerleider, L. G. (2002). Neural processing of emotional faces requires attention. Proceeding of the National Academy of 
Sciences, 99, 11458-11463.

Pfau, M., Haigh, M., Fifrick, A., Holl, D., Tedesco, A., Cope, J., ... Martin, M. (2006). The effects of print news photographs of the casualties of war. Journalism \& Mass Communication Quarterly, 83, 150-168.

Pieters, R., \& Wedel, M. (2004). Attention capture and transfer in advertising: Brand, pictorial, and text-size effects. Journal of Marketing, 68, 36-50.

Readence, J. E., \& Moore, D. W. (1981). A meta-analytic review of the effect of adjunct pictures on reading comprehension. Psychology in Schools, 18, 218-224.

Rosbergen, E., Pieters, R., \& Wedel, M. (1997). Visual attention to advertising: A segment-level analysis. Journal of Consumer Research, 24, 305-314.

Sengül, S., \& Dereli, M. (2013). The effect of learning integers using cartoons on 7th grade students' attitude to mathematics. Educational Sciences: Theory and Practice, $13,2526-2534$.

Seo, K., \& Dillard, J. P. (n.d.). The persuasive effects of two stylistic elements: Framing and imagery. Communication Research.

Seo, K., Dillard, J. P., \& Shen, F. (2013). The effects of message framing and visual image on persuasion. Communication Quarterly, 61, 564-583.

Shahab, L., Hall, S., \& Marteau, T. (2007). Showing smokers with vascular disease images of their arteries to motivate cessation: A pilot study. British Journal of Health Psychology, 12, 275-283.

Smith, R. A., Houston, M. J., \& Childers, T. L. (1985). The effects of schematic memory on imaginal information processing: An empirical assessment. Psychology and Marketing, 2, 13-29.

Süssenbach, P., Niemeier, S., \& Glock, S. (2013). Effects of and attention to graphic warning labels on cigarette packages. Psychology \& Health, 28, 1192-1206.

Tukachinsky, R., Mastro, D., \& King, A. (2011). Is a picture worth a thousand words? The effect of race-related visual and verbal exemplars on attitudes and support for social policies. Mass Communication and Society, 14, 720-742.

van Rompay, T. J. L., de Vries, P. W., \& van Venrooij, X. G. (2010). More than words: On the importance of picture-text congruence in the online environment. Journal of Interactive Marketing, 24, 22-30.

Verlhiac, J.-F., Chappé, J., \& Meyer, T. (2011). Do threatening messages change intentions to give up tobacco smoking? The role of argument framing and pictures of a healthy mouth versus an unhealthy mouth. Journal of Applied Social Psychology, 41, 2104-2122.

Whatley, S., Mamdani, M., \& Upshur, R. E. G. (2002). A randomised comparison of the effect of three patient information leaflet models on older patients treatment intentions. British Journal of General Practice, 52, 483-484.

Willnat, L., Graf, J., \& Brewer, P. R. (2000). Priming international affairs: How the media influence attitudes toward foreign countries. Paper presented at the annual meeting of the Association for Education in Journalism and Mass Communication, Phoenix, AZ.

Zillmann, D. (1999). Exemplification theory: Judging the whole by some of its parts. Media Psychology, 1, 69-94.

Zillmann, D. (2002). Exemplification theory of media influence. In J. Bryant \& D. Zillmann (Eds.), Media effects: Advances in theory and research (2nd ed., pp. 1941). Mahwah, New Jersey: Lawrence Erlbaum Associates. 